\title{
Sumando miradas: herramientas cartográficas para la interpelación colectiva del territorio
}

\author{
Aline da Fonseca, Lucía Eulén, ${ }^{2}$ Feline Schön, ${ }^{3}$ Beatriz Sosa ${ }^{4}$
}

Recibido: 30/3/2021; Aceptado: 07/07/2021

DOI: https://doi.org/10.37125/ISR.7.1.9

\section{Resumen}

La Plataforma Educativa de Ciencias en Malvín Norte funciona en el ámbito del Espacio de Formación Integral en la que docentes y estudiantes de Facultad de Ciencias realizan actividades educativas en conjunto con algunas escuelas de Malvín Norte. En este marco se presenta la experiencia Sumando miradas desarrollada con el objetivo de generar un espacio para reflexionar sobre la forma en la que construimos nuestra imagen del barrio y por tanto las maneras en las que nos relacionamos con/ en él. Partimos de la percepción subjetiva mediante mapas perceptivos, continuamos desde la visión individual esta vez mediada por la observación directa y la integración de recursos digitales disponibles en la plataforma del Plan Ceibal. Esta información es colectivizada y reorganizada en un proceso de cartografía participativa. Estas actividades se organizaron en tres talleres y una presentación en el marco de la muestra Feria de Cierre. Se aborda así el mapa como proceso cognitivo para pensar o proyectar acciones dentro del aula e incluso ampliarse a la comunidad educativa y el barrio mediante la deconstrucción de visiones territoriales preestablecidas. Además, se integra el uso de las TiC como una herramienta constructivista que puede generar nuevas experiencias en el proceso de aprendizaje. Esta experiencia es presentada en la Escuela de Verano de Plan Ceibal a los efectos de construir un espacio de diálogo entre educadores/formadores en el que el marco conceptual y los recursos didácticos elaborados puedan ser readaptados a nuevos contextos en el ámbito de la educación formal y no formal. Se resalta el potencial de la plataforma como promotor para la enseñanza de la ciencia en el ámbito escolar y la necesidad de trascender a otros contextos educativos.

Palabras clave: geografía; mapa perceptivo; cartografía participativa; Tic.

1 Laboratorio de Desarrollo Sustentable y Gestión Ambiental del Territorio, Instituto de Ecología y

Ciencias Ambientales (IECA), Facultad de Ciencias, Universidad de la República (Udelar).

https://orcid.org/oooo-0002-8494-0459 adafonseca@fcien.edu.uy.

2 Laboratorio de Desarrollo Sustentable y Gestión Ambiental del Territorio, IECA, Facultad de Ciencias, Udelar. https://orcid.org/oooo-0oo2-6082-5819 leluen@fcien.edu.uy.

3 Laboratorio de Desarrollo Sustentable y Gestión Ambiental del Territorio, IECA, Facultad de Ciencias, Udelar. https://orcid.org/oooo-ooo1-8222-5198 fschon@fcien.edu.uy.

4 Laboratorio de Desarrollo Sustentable y Gestión Ambiental del Territorio, IECA, Facultad de Ciencias, Udelar. https://orcid.org/oooo-0oo2-9259-0516 beatriz@fcien.edu.uy. 


\section{Introducción}

Las nuevas tecnologías están adquiriendo una presencia cada vez más destacada en nuestro cotidiano, proceso que se ha profundizado a partir de 2020 en el marco de la pandemia de covid-19 como resultado del incremento del trabajo virtual en la enseñanza, lo que plantea el desafío de su integración crítica al contexto de la educación formal en el que se encuentran inmerso en este proceso. En este marco, es importante señalar que donde hay que buscar las claves para comprender y valorar el impacto sobre la enseñanza y el aprendizaje de las tecnologías de la información y comunicación (TIC), no es en las TIC ni en sus características propias y específicas, sino en las actividades que llevan a cabo profesores ${ }^{5}$ estudiantes gracias a las posibilidades de comunicación, intercambio, acceso y procesamiento de la información que ellas ofrecen. En lo que concierne a la frecuencia de uso de las Tic en las aulas se articulan varios factores entre los que destaca la formación pedagógica del docente y sus concepciones previas sobre la utilidad educativa de estas tecnologías, también determinan su uso el dominio que los docentes tienen - o se atribuyen- de las TIC y su formación técnica (Coll, 2008).

En Uruguay, la incorporación de las Tic en la educación pública se articula principalmente en torno al Plan Ceibal, ${ }^{6}$ creado en 2007 , que constituye una oportunidad para desarrollar procesos de aprendizaje. En este sentido, se desarrolló el proyecto de extensión Sumando Miradas que, en una primera instancia, surge como parte constitutiva del Espacio de Formación Integral (EFI) ${ }^{7}$ Plataforma Educativa de Ciencias en Malvín Norte (PEC) a través de la propuesta Aprendiendo Geografía Usando los Dispositivos Ceibal; posteriormente se extiende al Plan Ceibal a través de la propuesta La Geolocalización y su Aplicación en el Aula.

Uno de los principales objetivos de Sumando Miradas es problematizar la forma de vincularnos con el barrio mediante diversas aproximaciones cartográficas, entre ellas las TIC, y, al mismo tiempo, actuar como dispositivo específico para el desarrollo de la integración de las funciones sustantivas de la Udelar y sus disciplinas a nivel curricular. La propuesta Aprendiendo Geografía Usando los Dispositivos Ceibal fue desarrollada en dos ediciones con docentes y estudiantes de Facultad de Ciencias y

5 Aclaración: No obstante la imposición lingüística acerca de los modelos de género, a efectos de hacer más fluida la lectura de este documento, se usará el masculino genérico, que en todos los casos refiere a ambos sexos.

6 Plan Ceibal es un plan de inclusión e igualdad de oportunidades para apoyar con tecnología a las políticas educativas uruguayas. Tiene como objetivo generar equidad en el acceso a la tecnología a estudiantes del sistema educativo y provee un conjunto de programas, recursos educativos y capacitación al servicio de los procesos de enseñanza y aprendizaje. https://www.ceibal.edu.uy/es/institucional

7 Un Espacio de Formación Integral es un dispositivo de la Universidad de la República (Udelar) que, a través de sus funciones (investigación, extensión y enseñanza), propone generar prácticas educativas interdisciplinarias que pongan en vínculo el territorio y sus actores. Son dispositivos flexibles, que pueden desarrollarse a partir de diferentes formatos como cursos, talleres, pasantías, proyectos, con diferentes cargas horaria y duración (semestral, anual, etc.), y tener diferentes formas de reconocimiento curricular según los servicios y las características del EFI. 
maestros y escolares de dos centros educativos del barrio Malvín Norte. En tanto, la propuesta La Geolocalización y su Aplicación en el Aula se desarrolló en dos ediciones en la Escuela de Verano de Plan Ceibal y constituyó un taller para la formación de formadores buscando un espacio de diálogo ${ }^{8}$ entre educadores y formadores en el que el marco conceptual y los recursos didácticos elaborados se socializaron para su readaptación a nuevos contextos en el ámbito de la educación formal y no formal.

Se parte de dos premisas: la necesidad de hacer extensión en cuanto práctica integral y la importancia de interpelarnos sobre la forma en la que construimos nuestra imagen del barrio y, por tanto, las maneras en las que actuamos y nos relacionamos con y en él, constituyendo distintos procesos de conformación de territorio y territorialidades. ${ }^{9}$ De esa manera, por un lado, entendemos que la integralidad, como clave de contradecir e interpelar las formas, procesos y productos sobre cómo aprendemos, enseñamos y conocemos se constituye en un abordaje que permite explicitar y problematizar las relaciones que se instalan en el territorio desde la perspectiva crítica (Haesbaert, 2004; Santos, 1996; Raffestin, 1980). En este marco se destaca el concepto de «ecología de saberes» propuesto por Boaventura de Sousa Santos (2006) como desafío teórico, metodológico, ético y epistemológico en cuanto

... conjunto de prácticas que promueven una nueva convivencia activa de saberes con el supuesto de que todos ellos, incluido el saber científico, se pueden enriquecer en ese diálogo. [...], sirve de base para la creación de comunidades epistémicas más amplias que convierten a la universidad en un espacio público de interconocimiento donde los ciudadanos y los grupos sociales pueden intervenir sin la posición exclusiva de aprendices (pp. 67-68).

Por otro lado, resaltamos la importancia del uso de distintas técnicas y herramientas de construcción cartográficas (Corbett et al., 2009; Risler y Ares, 2013) para trabajar la percepción e integración del conocimiento, que indagan y rescatan el sentido de pertenencia y apego al territorio, y que invitan a complejizar una visión limitada de este. Pues, como apunta Edgar Morin (2001), el debilitamiento de una percepción global conduce al debilitamiento del sentido de la solidaridad, pues cada uno no percibe más que su vínculo orgánico con su ciudad y sus conciudadanos. Cabe destacar que Malvín Norte es un barrio caracterizado por una alta densidad poblacional, con numerosos complejos habitacionales entre los que destacan Euskalerría 70, Euskalerría 71 y Euskalerría 92, cooperativas de vivienda, así como asentamientos irregulares y realojos, en un contexto socialmente vulnerado (Isach, Abbadie, Folgar, Schön y Da Fonseca, 2021).

8 En el presente documento se entiende el término diálogo como un constructo que va más allá del intercambio, generando a partir de este algo nuevo.

9 El concepto de territorio no se trabaja explícitamente con los escolares, pero si se aborda implícitamente cuando explicamos que existen distintas formas de apropiaciones y que estas pueden contener relaciones de poder o vincularse con rasgos identitarios. Cabe resaltar que los conceptos geográficos (lugar, espacio, territorio/territorialidades) adoptados son abordados desde el paradigma de la geografía crítica. 
Teniendo en cuenta esta complejidad característica del barrio se parte de la necesidad de explicitar dos niveles de percepción, el individual y el colectivo, para luego integrar las herramientas digitales disponibles en la plataforma del Plan Ceibal en una praxis que busca desnaturalizar el conocimiento en torno al barrio. En este sentido, se plantearon las siguientes preguntas ¿cómo perciben los niños su barrio, Malvín Norte? ¿Cómo cambia esta percepción mediante la utilización colectiva de técnicas de cartografía participativa y tecnologías digitales? ¿Contribuyen estas aproximaciones a la generación de espacios de integración?

El presente artículo se desarrolla en tres grandes apartados: en primer lugar, se explicita la propuesta llevada a cabo en las escuelas en el marco del EFI PEC en Malvín Norte, describiendo los contenidos y técnicas usados en los talleres; luego se aborda la experiencia en ámbito de formación a formadores (Escuela de Verano Plan Ceibal), y, por último, se busca reflexionar sobre el proceso y los aprendizajes resultantes.

\section{La experiencia Sumando Miradas}

\section{Aprendiendo Geografía Usando los Dispositivos Ceibal en el Espacio de Formación Integral Plataforma Educativa de Ciencias en Malvín Norte}

El EFI PEC es una propuesta coordinada por la Unidad de Extensión de Facultad de Ciencias que pretende fortalecer el vínculo de colaboración entre la facultad y otras instituciones educativas de Malvín Norte; en esta se desarrollan múltiples propuestas vinculadas a las distintas áreas de conocimiento. Como explicitan Patricia Iribarne, Stefany Horta y Marcela Ferreño (2017), el programa tiene por finalidad

... generar actividades colaborativas que permitieran a los estudiantes, investigadores y maestras indagar y experimentar de primera mano temas de ciencias naturales y exactas de una forma innovadora en los procesos de aprendizajes. A su vez, este programa se propone contribuir a la reflexión y análisis teórico/práctico sobre el rol de las actividades de comunicación, difusión, popularización y enseñanza de las ciencias por parte de los futuros profesionales.

En este marco, docentes del Laboratorio de Desarrollo Sustentable y Gestión Ambiental del Territorio (LDSGAT), del Instituto de Ecología y Ciencias Ambientales (IECA), implementaron la propuesta Aprendiendo Geografía Usando los Dispositivos Ceibal en los años 2017 y 2018, con escolares de cuarto año de las escuelas n. ${ }^{\circ} 267$ Euskadi y 268 Dr. Arturo Lussich de Malvín Norte (Figura 1). La propuesta constó de tres talleres y una presentación del trabajo en la Facultad de Ciencias en la Feria de Cierre que se lleva adelante anualmente (Figuras 2 y 3 ). 

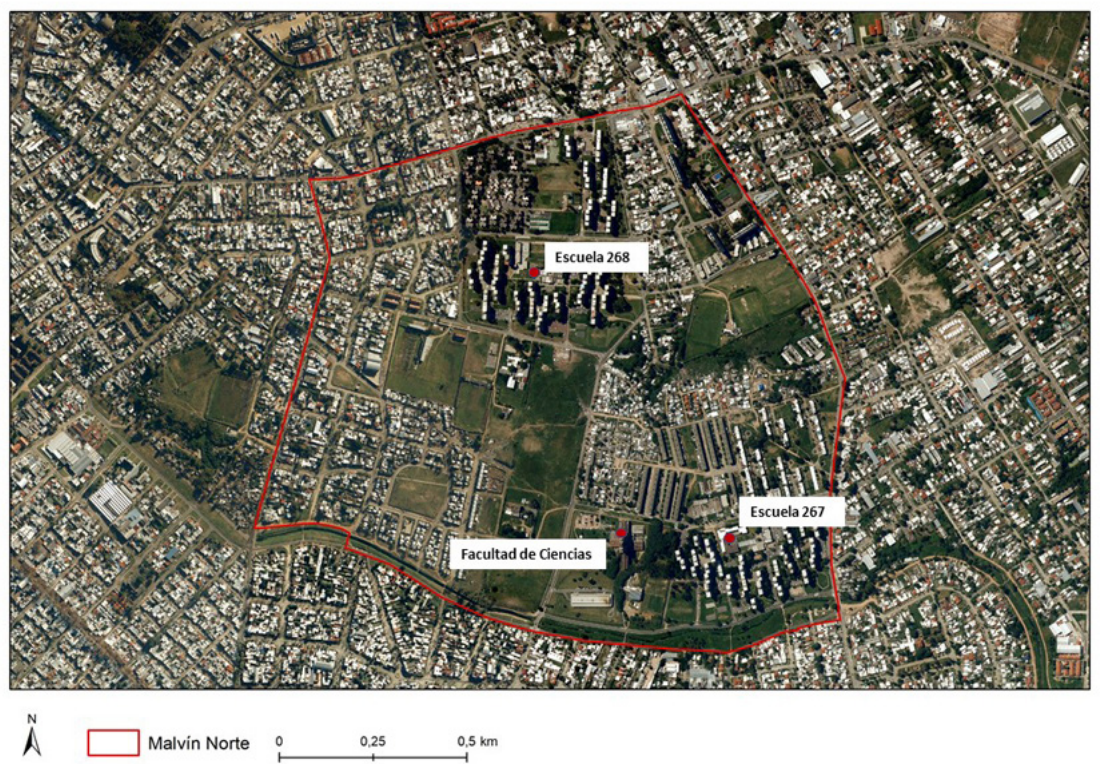

Fuente: elaboración propia a partir de imagen obtenida de https://visualizador.ide.uy/ideuy/core/ load_public_project/ideuy/.

La experiencia, que consiste en brindar herramientas para integrar el uso de las nuevas tecnologías en la enseñanza curricular de la Geografía, surge a partir de líneas de investigación que se desarrollan en el marco del LDSGAT, los contenidos curriculares presentes en el programa de Geografía de Educación Inicial y Primaria (Administración Nacional de Educación Pública [ANEP], Consejo de Educación Primaria [CEIP], 2008) vinculados a los temas de lenguajes cartográficos, sistemas de localización, representaciones espaciales (mapa, fotos aéreas, imágenes satelitales), conceptualización del lugar y del barrio; los recursos digitales disponibles en los dispositivos informáticos entregados a los alumnos por Plan Ceibal, específicamente los recursos de la categoría Territorializar presente en el portal_http://valijas.ceibal. edu.uy/; y del posterior intercambio con estudiantes provenientes de las licenciaturas en Geografía, Geología y Biología de la Facultad de Ciencias.

Antes de la instrumentación de los talleres en el aula, se llevó a cabo un encuentro con los maestros en el que se describieron las actividades y características de la propuesta a los efectos de incluir modificaciones y contextualizarla al grupo de estudiantes, 
y también con el cometido de generar un espacio para que los maestros pudieran integrar la propuesta a los contenidos programáticos en desarrollo.

Durante la ejecución de la propuesta en el aula, los contenidos curriculares, las herramientas TIC y la información generada por los estudiantes de facultad fueron integrados jerarquizando temas y conceptos claves para que los maestros puedan abordar en actividades pre y postaller.

\section{Figura 2. Esquema conceptual del diseño de los talleres. Elementos clave para la construcción del mapa temático del barrio}

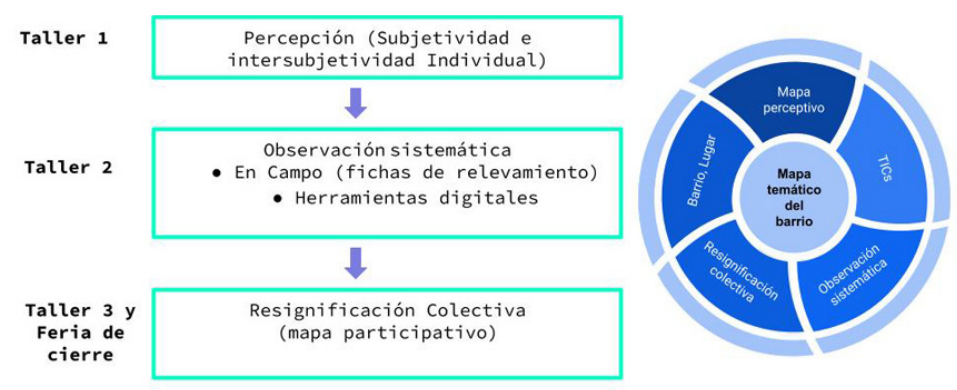

Fuente: elaboración propia.

El abordaje de los conceptos de lugar y de barrio son el disparador para identificar y problematizar los elementos materiales y las representaciones simbólicas en los que transcurre la vida social de los escolares. Se propone la reflexión conceptual a través de la realización de talleres con diversas actividades didácticas. Partiendo de la premisa que el taller es una forma de enseñar y, sobre todo, de aprender, se organizaron tres talleres.

Durante el primer taller, se les pidió a los niños que, en forma individual, dibujaran el barrio. La generalidad en la consigna planteada tiene como objetivo limitar las orientaciones, evitando sesgar la actividad en función de los planteos de los facilitadores del taller. De esta forma, se elaboró un mapa perceptivo que apela a la memoria y destaca, por tanto, el componente subjetivo. Esta técnica permite el reconocimiento de los elementos significativos del territorio, así como la organización y la representación de información en forma sencilla, espontánea y creativa (De Alba, 2004).

Luego, se colectivizaron los mapas elaborados y se compararon con mapas elaborados previamente por estudiantes de Facultad de Ciencias. A través de la observación de los dibujos se explicita que todos tenemos interiorizada una idea de barrio que es distinta a la de los demás. La forma de vivenciar el barrio, el lugar, la ciudad, tiene que ver con 
la percepción y sentido de pertenencia, emoción que hace una forma única de vivir el barrio, al mismo tiempo que constituye diversas formas de apropiaciones.

El barrio representa el territorio donde se expresan las relaciones de proximidad o de vecindad, apropiado y reconocido por sus habitantes o quienes transitan y actúan en él, otorgándole significados (Abbadie et al., 2019). En la conceptualización de barrio se trasciende el espacio geográfico, y establece un vínculo emocional con él, que lo transforma, por un lado, en un lugar (Tuan, 1990), y por otro en territorio con distintas apropiaciones y relaciones de poder (Saquet, 2015). Se construye así un ámbito, donde se suman miradas que trascienden desde la percepción individual a la colectiva, mi barrio, el de mi compañero, el nuestro.

El taller finaliza con la presentación de una actividad domiciliaria en la cual los niños seleccionan un lugar del barrio, lo visitan y completan una ficha de observación. ${ }^{10} \mathrm{Se}$ discute sobre las potencialidades de la observación pautada como estrategia de sistematización y relevamiento de información que permite luego ser analizada. Se suma así una nueva mirada a nivel individual, se transita desde la percepción subjetiva, a la observación sistemática y explícita mediada por los sentidos.

En el segundo taller se presentan y analizan los resultados de las actividades. Se genera un espacio en el que se discute sobre las diferencias entre la percepción subjetiva - lo que tenemos en nuestras cabezas- y la observación mediada por los sentidos y hecha en forma sistemática. El taller continúa con la presentación de las herramientas digitales de teledetección (fotos aéreas, imágenes satelitales e imágenes tomadas con Dron), como instrumentos que nos permiten adquirir nueva información. Se resalta el hecho de que estas herramientas nos permiten complementar y potenciar nuestros sentidos y acercarnos a otro modo de abordar el mismo objeto de estudio. Por ejemplo, se pueden ver cambios en el barrio mirando imágenes satelitales del presente y de fechas anteriores, podemos enfocarnos en el detalle de un área que nos interese o en el contexto en el que está inmersa, cambiando la escala de observación.

Posteriormente, los niños realizan un conjunto de actividades con la aplicación Google Maps de la plataforma del Plan Ceibal, ayudados por un tutorial elaborado por los docentes y estudiantes universitarios. El taller finaliza con una discusión acerca del uso de la tecnología en nuestro cotidiano y su utilidad; que, en este caso, permite ampliar la capacidad de observación. Se problematiza sobre la relevancia del uso reflexivo de la tecnología. Sumamos así otra mirada, la mediada por las herramientas digitales de teledetección y de la aplicación Google Maps. ${ }^{11}$

10 La ficha de observación «Acercando la mirada. Relevamiento de campo» constituye un registro de datos sobre el observador, la caracterización del sitio relevado (localización, fecha de relevamiento, estado del tiempo, registro fotográfico), y percepción del lugar seleccionado (¿Qué veo?; Este lugar es importante para mí porque...; Me gusta porque...; No me gusta porque...).

11 https://www.google.com.uy/maps. 
El tercer taller retoma la mirada desde nosotros y se construye de forma colectiva el mapa del barrio. Desde el inicio de la propuesta se ha trabajado explicitando la percepción subjetiva, que ha sido enriquecida mediante la observación sistemática en el propio territorio y mediante las posibilidades de visualización que brindan las herramientas digitales. Entonces, ¿qué es el barrio? y antes y quizá más importante, ¿qué queremos mostrar?, ¿con qué intención vamos a construir un mapa? Se discuten sobre estos aspectos, por medio de la presentación de distintos tipos de cartografías además de los elementos constitutivos de un mapa, comenzando por su título, donde se explicita la intencionalidad del mapa. Para este taller, se elaboró un mapa base que consta de una delimitación territorial definida según el trabajo de los niños en los talleres anteriores. Sobre este mapa, los niños definen el título y, mediante referencias, posicionan los distintos elementos que deberían estar presentes en ese mapa.

La construcción del mapa colectivo acontece mediante dos actividades simultáneas. De modo individual, sobre un mapa base a escala A4, cada niño localiza espacialmente los lugares relevados en la ficha de campo ayudándose para ello con Google Maps. Luego, pasan al pizarrón para la sistematización de sus resultados y el armado del mapa colaborativo. La suma de miradas finaliza de esta forma, con un mapa que integra las percepciones y observaciones de los integrantes del grupo. Se intenta así resignificar en forma colectiva los conceptos abordados en los talleres anteriores que se materializan en la creación de un mapa temático del barrio, elaborado y contextualizado en conjunto por los escolares y sus maestros.

La experiencia trasciende el espacio del aula y los espacios vividos por los escolares y es socializada en una Feria de Cierre en la Facultad de Ciencias. En esta instancia se hace explícita la apropiación de la propuesta vivenciada en aula por parte de los escolares. Así, en el aprendizaje significativo, se reapropian de la experiencia y crean nuevas propuestas que dialogan con los conocimientos aprehendidos, a la vez que intercambian sus experiencias a través de la exposición del mapa generado y su proceso de construcción. Mediante una actividad propuesta e impartida por los escolares con los visitantes, se utilizan los recursos digitales para integrar nuevos elementos en el mapa temático del barrio. El mapa sigue creciendo, porque cada nueva participación suma miradas al mapa global y rescata así el carácter dinámico de los mapas según los actores que hacen parte de su construcción. 
Figura 3.

Imágenes de distintas etapas de la experiencia Aprendiendo Geografía Usando los Dispositivos Ceibal.

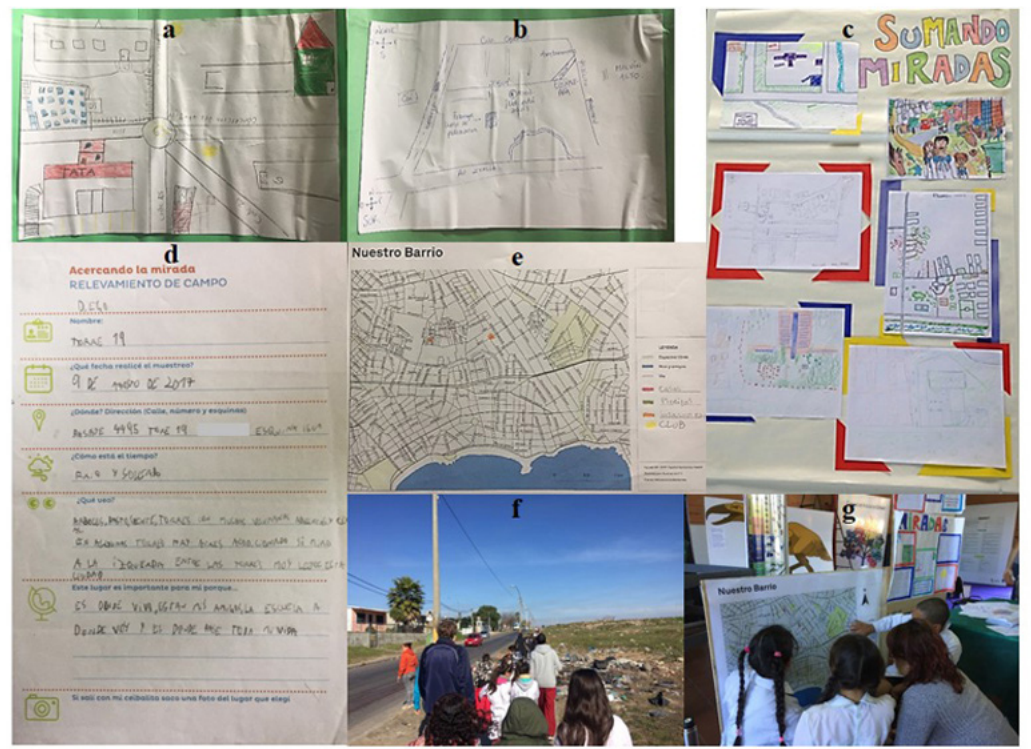

a) Mapa perceptivo elaborado por un escolar de 4.0 año. b) Mapa perceptivo elaborado por un estudiante de Facultad de Ciencias. c) Cartelera escolar Sumando Miradas. d) Fichas de observación en terreno. e) Mapa base. f) Recorrido de la escuela hacia facultad. g) Mapa participativo en la Feria de Cierre

Fuente: elaboración propia.

\section{La geolocalización y su aplicación en el aula}

\section{en la Formación de formadores: Escuela de Verano de Plan Ceibal}

Con el objetivo de brindar herramientas a los docentes, de distintos niveles y distintas disciplinas, para el abordaje de lo territorial y el uso de herramientas digitales; esta propuesta se presentó en las ediciones 2020 y 2021 de la Escuela de Verano de Plan Ceibal en el área temática convivir, comprender, expresar o diseñar con el título de La geolocalización y su aplicación en el aula. Estos talleres, de un total de tres horas de duración, fueron dictados por el equipo docente que coordinó esta propuesta y en ellos se presentó la experiencia detallada anteriormente (Figura 4). 
Figura 4.

Imágenes de distintas etapas de la experiencia La geolocalización y su aplicación en el aula, Escuela de Verano Ceibal.

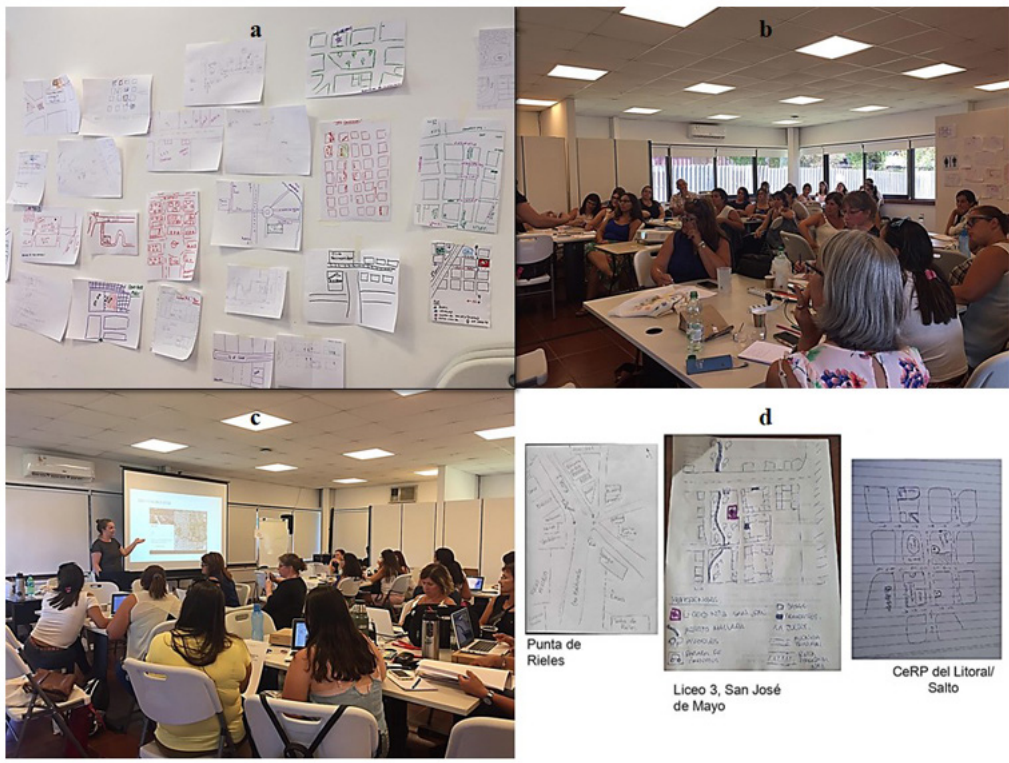

a) Mapas perceptivos elaborados por los docentes. b y c) Instancia de taller. d) Mapas perceptivos hechos por los docentes en la aplicación Jamboard.

Fuente: elaboración propia.

El taller comienza de la misma forma que en la escuela, es decir, pidiendo a los docentes que dibujen el mapa del barrio de un centro educativo en el que trabajan. Luego se colectivizan los dibujos y se describen los elementos que presentan los mapas con énfasis en la identificación de la presencia de elementos orgánicos, funcionales al docente (paradas de ómnibus, almacenes, estaciones de servicios) y elementos significativos desde el punto de vista afectivo. Esta instancia es muy relevante ya que explicita el tipo de vínculo que genera el docente con el centro educativo en el que trabaja y le permite interpelarse sobre las razones que lo determinan. Se desarrollan además varios aspectos relacionados a la utilidad del uso de esta herramienta en el aula, lo que permite identificar los vínculos y relaciones que se generan entre los estudiantes, el barrio y el centro educativo. Se enfatiza en la importancia tanto de la información que se representa en el mapa y sus valoraciones como de los elementos que pertenecen al territorio, pero que no se dibujan en los mapas (el cero es dato), permitiendo interrogarse al respecto de qué factores determinan la ausencia de determinados elementos en los mapas perceptivos. Se reflexiona sobre el vínculo entre la geolocalización-georreferenciación de los elementos cartográficos y la percepción, 
el sentido de pertenencia, identidad y apego que refleja la intención sobre estos. Así, se pretende contribuir a generar espacios de reflexión y problematización con los docentes sobre el ejercicio cartográfico en el aula para avanzar hacia la construcción del concepto de territorio como categoría densa, compleja que contiene a la historia que lo contiene (Achkar, 2010).

Luego, se presentan los principales contenidos abordados en el segundo y tercer taller, disponibilizando todo el material elaborado para su implementación (ficha de observación, tutorial para el uso de Google Maps). Durante esta presentación se procura generar una instancia de diálogo en la que los docentes presentan sus experiencias de trabajo en el aula.

En los talleres de Plan Ceibal se presenta también las plataformas de bases de datos espaciales del país y de disponibilidad libre a las que se pueden acceder como recurso didáctico para observar, caracterizar el barrio, analizar las dinámicas espacio-temporales y profundizar los procesos de enseñanza-aprendizaje y creación en el aula.

\section{En diálogo con las experiencias}

La propuesta desarrollada en el marco del EFI PEC, construida de modo colaborativo entre estudiantes, docentes universitarios y maestros, permitió a la comunidad educativa realizar un aprendizaje contextualizado del contenido del programa curricular de Geografía, y adquirir además habilidades para el manejo de herramientas tecnológicas. De esta manera, se compartió una experiencia donde la praxis retroalimenta los contenidos teóricos y metodológico-didácticos, generando nuevas relaciones dialécticas entre los centros educativos participantes.

En cuanto a los contenidos teóricos, la experiencia en su conjunto destaca el valor del mapeo participativo y las cartografías como una herramienta que contribuye a la comprensión del mapa como acto político (Sletto, Bryan, Torrado, Hale y Barry, 2013), en que a través de las representaciones espaciales se construye un sentido de identidad común, que parte del plano individual (Talleres 1 y 2) y se extiende en relación con el otro, transformándose en una construcción colectiva, la clase, la escuela, las instituciones del barrio, el lugar de la comunidad educativa (Taller 3).

En este marco el mapa, al actuar de eje estructurante, se constituyó tanto en un fin como en un medio pedagógico en el que se entretejieron y articularon los contenidos curriculares, la percepción individual y sus significados personales mediante la elaboración del mapa perceptivo y también, mediante su socialización, la comprensión y reconocimiento del otro. En este proceso se explicitaron las conceptualizaciones subjetivas (Taller 1), y el proceso sistemático de observación mediado por nuestros sentidos y ampliado a través del uso de tecnologías, que se integran al proceso de enseñanza-aprendizaje añadiéndole valor en conformidad con el planteo de César Coll (2008). En concomitancia, se destaca que el mapa permite reconocer la información ambiental especializada, analizarla y comprenderla y, por lo tanto, posicionarnos 
sobre las configuraciones territoriales de las que somos parte, lo que permite la deconstrucción de esa realidad, que muchas veces se da por establecida en los mapas «tradicionales» (Álvarez-Larrain y McCall, 2019). En este punto, en la construcción colectiva del mapa «de la clase», se sistematiza una construcción que identifica lo «común», capaz de ser representado en variables georreferenciadas, cuantificadas, categorizadas, analizadas. De esa manera, el mapa, como proceso cognitivo, puede transformarse en el punto de partida desde donde reflexionar, pensar o proyectar acciones dentro del aula e incluso ampliarse a la comunidad educativa y del barrio, y así deconstruir las visiones territoriales establecidas como acción política de reconocimiento del otro y sus intereses (Gil y Gómez, 2019).

Trabajar el barrio en la escuela desde la percepción, redimensiona al mapa como resultado de un trabajo colectivo que cumple una función a la interna del colectivo para poder pensar los lugares, apropiarse, empoderarse como ciudadanos y así poder transformar nuestras relaciones con el territorio. En este sentido, la presentación de esta experiencia en la muestra del EFI PEC constituyó un ejemplo en que el «mapa de la clase» trascendió sus límites para rescatar los trayectos vividos por quienes habitan ese espacio común e invitan a otros identificar elementos en el mapa o a integrar nuevos. Así, el mapa develó su carácter dinámico convocando a sumar a otros a reconocerse, a ser parte; esto explicita, por tanto, su potencialidad en la creación de sentido de una identidad colectiva. Incluso como punto de partida para abordar la otredad. Aquí se visualiza el potencial de esta metodología para generar espacios que permitan reflexionar sobre la integración barrial de Malvín Norte trascendiendo el ámbito escolar.

Por otra parte, en esta experiencia también se destaca el potencial del uso de las TIC en los procesos educativos y formativos, más aún en momentos de una pandemia como la que vivimos en la actualidad. Aun así, no debería ser la única herramienta que se implemente (Coll, 2008); en esta experiencia, el uso de las Tic se integró a la construcción de conocimientos con combinación de experiencia, interpretación e interacciones estructuradas entre los integrantes del aula. Por esto, el alumno activo aprende mejor que un alumno en un rol pasivo, donde recibe solo la información, como señala Paulo Freire (1968) cuando hace alusión al modelo de educación «bancaria». El uso de las TIC, en este contexto, brinda una herramienta constructivista que puede generar nuevas experiencias en el proceso de aprendizaje porque pone al alumno en un rol activo (Hernández, 2008). Por ejemplo, las consignas propuestas a los escolares para localizar su casa y la escuela, mediante el uso de Google Maps, motivó su interés por conocer otros elementos del barrio, y además trascendió su entorno inmediato al buscar la localización de ciudades de otros países y continentes. En tal sentido, se destaca la apropiación de la herramienta y su potencial para abordar diversas temáticas vinculadas a los intereses de los escolares. Se generó un espacio para la reflexión acerca de las posibilidades que nos brindan tales tecnologías y la necesidad de su uso reflexivo y crítico para el análisis territorial y comprensión de las complejidades ambientales. 
Esta experiencia irrumpió en el proceso educativo desarrollado en el aula y por tanto constituyó una experiencia limitada a tres talleres. Las limitantes de tiempo y número de instancias han sido identificadas como debilidades en la implementación del programa EFI PEC (Iribarne et al., 2017). En tal sentido, para la apropiación y desarrollo de esta propuesta resultó fundamental el intercambio entre los docentes-educadores reconociendo que será el maestro quien sostendrá y dirigirá el proceso y las múltiples posibilidades de desarrollo que esta propuesta plantea. Se destaca entonces la relevancia de construir espacios conjuntos con los docentes que permitan abordar aspectos conceptuales y metodológicos acorde a los tiempos educativos del grupo de escolares y los contenidos programáticos que el maestro efectivamente desarrollará en su planificación anual. Durante el desarrollo de esta propuesta se organizaron instancias de intercambio con los maestros que permitieron su ajuste y la generación de recursos didácticos acordes a los intereses y necesidades planteadas. En este punto destacamos que, más que las limitantes de duración y frecuencia de los talleres desarrollados en el aula, el aspecto clave en relación con la construcción de procesos educativos significativos se centra en la apropiación de los maestros que son en definitiva los conductores de estos procesos.

En este marco, resaltamos la pertinencia de promover instancias de articulación e intercambio junto con maestros, docentes y estudiantes de Facultad de Ciencias que participarán de la propuesta educativa en consonancia con Iribarne et al. (2017). Desde el EFI PEC se ha avanzado en la organización de un módulo teórico previo al inicio de las actividades en las escuelas, de carácter obligatorio para los estudiantes a los que pueden asistir también los docentes, donde se reflexiona sobre distintos elementos del quehacer educativo: vínculo ciencia-sociedad, extensión, interdisciplina; contexto socio territorial de Malvín Norte; el proceso de enseñanza y aprendizaje de las ciencias en la escuela. Si bien no se desconocen las dificultades operativas en la construcción de estos espacios, la participación de los maestros fortalecería la praxis educativa enriqueciendo el vínculo entre la Facultad de Ciencias y las instituciones educativas nucleadas en torno al EFI PEC.

Resulta también importante destacar la pertinencia de generar espacios que promuevan las experiencias desarrolladas en el marco del EFI PEC más allá del ámbito de Malvín Norte. Esto permitiría adaptarlas a otros contextos de enseñanza, para reflexionar sobre la praxis docente, su rol docente, la transversalización de los temas curriculares acorde a la realidad de los educandos e incentivar el desarrollo de ideas para la construcción de nuevas propuestas educativas. En tal sentido, se destaca la buena evaluación de la presente propuesta en el marco del espacio de formación a formadores articulado por la Escuela de Verano del Plan Ceibal; ambas ediciones recibieron nivel de satisfacción general de 78-79 \% muy satisfactorio (Ceibal, 2021; 2020). Cabe señalar también que luego del taller presencial dictado en 2020 el equipo docente recibió la invitación de organizar otra actividad en el marco del Programa PAEPu del Codicen (Proyecto de Apoyo a la Mejora de la Calidad de la Educación Inicial y Primaria en Uruguay) para la formación de formadores regionales del área 
de Ciencias Sociales que trabajan con maestros de escuelas de tiempo completo de todo el país. Si bien debido a la situación de pandemia esta actividad no se llevó a cabo, se pone en evidencia la pertinencia de potenciar y articular instancias de formación de formadores que tendrían la particularidad de presentar experiencias concretas lo que facilita su readaptación a la vez que constituye una instancia de intercambio que enriquece al conjunto de los participantes.

El conjunto de estas reflexiones apoya el planteo de Iribarne et al. (2017) e Iribarne, Eliana Arismendi, Horta, Laura Bruzzone y Soledad Camacho (2019), quienes sostienen que el desarrollo de estas experiencias supone un espacio innovador para acercar la ciencia a la escuela primaria y despierte el interés de los escolares. Asimismo, constituye un espacio de formación integral para los estudiantes universitarios, quienes, al vivenciar la práctica, adquieren habilidades de trabajo en grupo y comparten y adecuan el conocimiento científico para su divulgación con los escolares, a la vez que estrechan el vínculo entre los docentes y estudiantes y generan lazos de confianza al trabajar en la creación de los talleres de modo colaborativo. De esta forma, la experiencia se configura en un espacio para vincular la extensión con la enseñanza y promover el desarrollo académico y la formación disciplinaria curricular, contextualizada en consonancia con la concepción de extensión en su dimensión pedagógica en cuanto metodología de aprendizaje integral y humanizadora, donde no hay roles estereotipados y todos pueden aprender y enseñar (Universidad de la República [Udelar], 2009).

Continuar y fortalecer el desarrollo de estas experiencias articuladas en un programa más amplio debiera constituirse en un proyecto que dinamice y catalice la enseñanza de las ciencias en el ámbito escolar. Esto adquiere fundamental importancia si se considera que en la gran mayoría de los mapas perceptivos dibujados por los niños no se señalaba a la facultad; y cuando el edificio se dibujaba presentaba grandes dimensiones a modo de castillo presentándose como un «inalcanzable». En tal sentido, esta experiencia permitió interpelar al equipo docente sobre la relación que establece como «vecino» en un territorio; pero, además, instala la necesidad de interpelar sobre los modos en que la ciencia (en este caso a través de una facultad) es percibida por los escolares. A modo de propuesta, resulta pertinente proponer una síntesis de las distintas experiencias desarrolladas en el EFI PEC con énfasis en las modalidades de percepción de la actividad científica. Este análisis debiera incorporar los aportes de todos los involucrados: maestros, escolares, estudiantes y docentes de Facultad de Ciencias, y también a los vecinos. Se generaría así un insumo orientador para articular las distintas propuestas desarrolladas en la Plataforma en un marco común que promoviera la reflexión crítica sobre la enseñanza de las ciencias en la escuela. Además, este análisis debiera retroalimentarse en instancias de formación de formadores, y otros ámbitos educativos.

Profundizar sobre el quehacer científico y los procesos de enseñanza-aprendizaje entorno a este, así como establecer un diálogo de saberes entre actores e instituciones sociales en los ámbitos educativos resulta de especial relevancia no solo como elemento motivador en la formación de futuros científicos, sino y sobre todo porque al 
familiarizarse con la actividad científica se internalizan conocimientos para identificar y resolver problemas que permitan abordar los desafíos del presente siglo (Arteaga, Armada y Del Sol, 2016). De esta forma, se desarrollaría el proceso de extensión entendido como «un proceso dialógico y bidireccional que redimensiona a la enseñanza, al aprendizaje y a la investigación» (Udelar, 2009).

\section{Agradecimientos}

Al trabajo colaborativo con Valentina Otero, Agustín Urtiaga y Romina Sanabria en la elaboración de los talleres, actividades didácticas y tutoriales de Google Maps.

A las maestras Daniela Fellay y Rocío Curtina, a los estudiantes de cuarto grado de los años 2017-2018, y a las escuelas n.$^{\text {os }} 268$ y 267 por el compromiso, el apoyo y la retroalimentación para la generación de los recursos didácticos y prácticas desarrolladas.

Al Espacio de Formación Integral Plataforma Educativa de Ciencias en Malvín Norte por la posibilidad de participar, la disponibilidad y los recursos dispuestos.

Al Plan Ceibal por promover encuentros para el diálogo con formadores y la reflexión en torno al quehacer educativo.

Todos los autores contribuyeron por igual al presente trabajo.

\section{Referencias}

Abbadie, L., Bozzo, L., Da Fonseca, A., Folgar, L., Isach, L., Rocco, B.,...Viñar, M.E. (2019). Del barrio a las territorialidades barriales: revisitando categorías desde experiencias de trabajo en cuatro barrios de Montevideo. En S. Aguiar, V. Borras, L. Fernández y M. Pérez (Eds.), Habitar Montevideo: 21 miradas sobre la ciudad (pp. 275-301). Montevideo: La Diaria-Intendencia de Montevideo. Recuperado de https://www.fes-uruguay.org/fileadmin/user_upload/Habitar_ Montevideo.pdf.

AChKar, M. (2010). Territorio ¿Concepto clave para analizar las transformaciones en el siglo Xxi? En A. Domínguez y L. Pesce (Eds.), Lecturas y análisis desde la(s) geografía(s) 2 (pp. 145-153). Montevideo: Departamento de Geografía, CFE, ANEP.

Álvarez-Larrain, A., y McCall, M. K. (2019). Herramientas y actividades de mapeo participativo para estudios de arqueología del paisaje. En P. S. Urquijo Torres y A. Vieyra (Eds.), Geografía y ambiente desde lo local (pp. 277-304). Ciudad de México: CIGA, UnAM.

Administración Nacional de Educación Pública (ANEP), Consejo de Educación Primaria (CEIP) (2008). Programa de Educación Inicial y Primaria. Montevideo: ANEP, CEIP.

Arteaga, E., Armada, L., y Del Sol, J. L. (2016). La enseñanza de las ciencias en el nuevo milenio. Retos y sugerencias. Revista Universidad y Sociedad, 8(1), 169-176.

Coll, C. (2008). Aprender y enseñar con las TIC: expectativas, realidad y potencialidades. Boletín de la Institución Libre de Enseñanza, 72(1), 7-40.

Corbett, J., Devos, S., Di Gessa, S., Fara, K., Firmian, I., Liversage, H., ... Omar, R. (2009). Buenas prácticas en cartografía participativa. Análisis preparatorio para el Fondo Internacional de Desarrollo Agrícola (FIDA). Roma: FIDA. 
De Alba, M. (2004). Mapas mentales de la Ciudad de México: una aproximación psicosocial al estudio de las representaciones espaciales. Estudios Demográficos y Urbanos, 19(1), 115-143. Recuperado de https://doi.org/10.24201/edu.v19i1.1197.

De Sousa Santos, B. (2006). Renovar la teoría crítica y reinventar la emancipación social (encuentros en Buenos Aires). Buenos Aires: Clacso. Recuperado de http://biblioteca.clacso.edu.ar/clacso/coediciones/20100825032342/critica.pdf.

Freire, P. (1968). Pedagogía del oprimido. Buenos Aires: Siglo Veintiuno Editores.

GIL, N. I., y Gómez, J. I. (2019). La cartografía participativa como herramienta para la acción política, dos estudios de caso en espacios rurales y urbanos en Colombia. Cardinalis, (12), 290-316.

Haesbaert, R. (2004). Dos Múltiplos Territórios à Multiterritorialidade. En Seminário Nacional sobre Múltiplas Territorialidades, 1. Porto Alegre: Anais. Recuperado de https://www.ufrgs.br/petgea/ Artigo/rh.pdf

Hernández, S. (2008). El modelo constructivista con las nuevas tecnologías: aplicado en el proceso de aprendizaje. RUSC. Universities and Knowledge Society Journal, 5(2), 26-35.

Iribarne, P., Horta, S., y Ferreño, M. (2017). Extensión universitaria, prácticas integrales y trans-formación de la enseñanza: el caso de la Plataforma de Ciencias en Malvín Norte. Jornadas de Investigación en Educación Superior. Montevideo: CSE, Universidad de la República.

Iribarne, P.; Arismendi, E.; Horta, S.; Bruzzone, L., y Camacho, S. (2019). Unidad de Extensión de Facultad de Ciencias: creación, consolidación y perspectivas. En Tejer la red: experiencias de extensión desde los servicios universitarios 2008-2018 (pp. 211-221). Montevideo: SCEAM, Universidad de la República. Recuperado de https://www.extension.udelar.edu.uy/wp-content/ uploads/2019/12/CSEAM_Tejer-la-red_DIGITAL_compressed.pdf.

Isach, L., Abbadie, L., Folgar, L., Schön, F., y Da Fonseca, A. (2021). Entre Malvín Norte y Punta de Rieles: poniendo en diálogo sus territorialidades y representaciones. En M. PÉrez SánChez, L. Abbadie, J. Alves, L. Folgar y L. Isach, Territorio e integralidad: experimentando lo común (pp. 83-102). Montevideo: Programa Integral Metropolitano-CSEAM, Universidad de la República.

Morin, E. (2001). La cabeza bien puesta. Repensar la reforma. Reformar el pensamiento. Buenos Aires: Nueva Visión.

Raffestin, C. (1980). Por uma geografia do poder. San Pablo: Ática.

Risler, J., y ARes, P. (2013) Manual de mapeo colectivo. Recursos cartográficos críticos para procesos territoriales de creación colaborativa. Buenos Aires: Tinta Limón.

Santos, M. (1996). A natureza do espaço. Técnica e Tempo. Razão e Emoção. San Pablo: Hucitec.

SAQUet, M. A. (2015). Por una geografía de las territorialidades y las temporalidades. Una concepción multidimensional orientada a la cooperación y el desarrollo territorial. La Plata: FAHCE, Universidad Nacional de La Plata. Recuperado de http://www.libros.fahce.unlp.edu.ar/index.php/libros/ catalog/book/50.

Sletto, B., Bryan, J., Torrado, M., Hale, Ch., y Barry, D. (2013). Territorialidad, mapeo participativo y política sobre los recursos naturales: la experiencia de América Latina. Cuadernos de Geografía: Revista Colombiana de Geografía, 22(2), 193-310.

Tuan, Y. (1990). Topophilia: A study of environmental perception, attitudes, and values. Nueva York: Columbia University Press.

Universidad de la República, Consejo Directivo Central (2009, octubre 27). Para la renovación de la enseñanza y la curricularización de la extensión y las actividades en el medio. (Resolución n. ${ }^{\circ}$ 5). Recuperado de http://www.expe.edu.uy/expe/resoluci. nsf/4e1fd2c2a317193ao3256dccoo3b9o2f/f200247a7f556d23032576550069eo6o. 